\section{Spectrum of Atmospheric Turbulence}

DR. E. C. S. MEGAW ${ }^{1}$ opens his valuable contribution to this subject with a challenging remark. He says, "knowledge of the average properties of turbulence in the free atmosphere is almost totally lacking". Actually, so many meteorologists have published observations that it would be impossible here to give an adequate list of them. As long ago as 1926, I summarized the available facts in the statement that the diffusivity for neighbours is roughly proportional to the four-thirds power of their separation ${ }^{2}$. That was an empirical induction from observations : the accompanying theory was an aid to description, and did not use any dynamical hypothesis. The separations ranged from $10^{8} \mathrm{~cm}$. (Defant ${ }^{3}$ ) to $30 \mathrm{~cm}$. (Richardson ${ }^{4}$ ). The theory afterwards started by Kolmogoroff to which Dr. Megaw refers is an independent and fascinating intellectual creation, based on energy and the theory of physical dimensions. Recently, Batchelor 5 has related it to the aforesaid summary of observations. The behaviour of sea water is, strange to say, also relevant'. These objections to Dr. Megaw's opening paragraph do not in the least detract from the merit of the rest of his publication.

Hillside House,

Kilmun, Argyll. Jan. 14

1 Megaw, E. C. S., Nature, 168, 1100 (1950).

3 Richardson, I. F., Proc. Roy. Soc., A, 110, 709 (1926).

${ }^{3}$ Defant, A., Wien Akad. Sitzb., IIa, 130, 401 (1921).

"Richardson, . .. F., Beiträge z. Phys. d. Freien Atm. Hergesell Festschrift, 25 (1929).

${ }^{5}$ Batchelor, G. K., Quart. J. Roy. Met. Soc., 76, 133 (1950).

${ }^{B}$ Richardson, L. F., and Stommel, H., J. Met., 5, 238 (1948).

THE remark which Dr. Richardson criticizes was not made without some consideration of the contributions and views of the many meteorologists to whom he refers; and I believe a number of them would not dispute its rough justice. I admit, however, that I did not, at a first reading, properly appreciate the significance of Dr. Richardson's empirical discovery ${ }^{1}$ twenty-five years ago of the four-thirds-power law of 'diffusivity for neighbours'. Had its equivalence to a statement about the correlation between velocity differences and so about the spectrum of turbulence-which was, in fact, noted by Obukhoff ${ }^{2}$ and by von Weizsäcker ${ }^{3}$ in their original contributions to the similarity theory--been generally recognized at an earlier date, this discovery would doubtless have found the place in standard works on meteorology which it deserves.

The inclusion, in the observations from which Dr. Richardson ${ }^{x}$ made his deduction, of a point corre. sponding to diffusion by purely molecular viscosity may have helped to obscure the issue. At the opposite end of the spectrum, the apparent consistency of Defant's figures for cyclonic eirculation with a relationship which now finds support in a theory based on a postulate of spherical isotropy is a surprising result. It reinforces my conclusion that we still have much to learn about the large-eddy end, at least, of the spectrum of atmospheric turbulence.

Royal Naval Scientific Service.

E. C. S. Megaw

Jan. 18.

${ }^{1}$ Richardson, L. F., Proc. Roy. Soc., A, 110, 709 (1926). 2 Obukhoff, A. M., Bull. Acad. Sci. U.S.S.R. (Geog. and Geophys.),
Nos. 4-5, 453 (1941).

'Von Weizsăcker, C. F., Z. Phys., 124, 614 (1948).

\section{Combined Effects of X-Rays and Tempera- ture on Mitosis}

BROADLY speaking, the visible effects of ionizing radiations on the nucleus are of two kinds : first, the breakage of the chromosomes at sensitive phases of the nuclear cycle; secondly, the 'primary' effect of irradiation (stickiness), which may be typified as a condition showing fluidity of chromosome outline, internal vacuolation and adhesion of sister chromatids at anaphase. In Trillium root-tips, with a dose of $90 \mathrm{r}$. X-rays and at $20^{\circ} \mathrm{C}$., its onset would precede that of the chromosome breaks, appearing at four to five hours after irradiation. The onset, intensity and spread of both effects is subject to the kind of ionization, the dose and environmental factors ${ }^{1}$.

Recent experiments have proved enlightening on these questions. These experiments were designed to test whether normally charged heterochromatin cold-starved of deoxyribose nucleic acid could be directly broken at metaphase by X-rays. For this purpose plants of Trillium grandiflorum were chilled at $0-3^{\circ} \mathrm{C}$. for three days prior to irradiation of the root-tips. A dose of $90 \mathrm{r}$. was used, and during irradiation the plants (with washed roots) were brought to $20^{\circ} \mathrm{C}$. and kept at this temperature afterwards. Fixations were then made; some immediately, and others at half-hourly intervals terminating at $7 \mathrm{hr}$., followed by a final fixation after $24 \mathrm{hr}$.

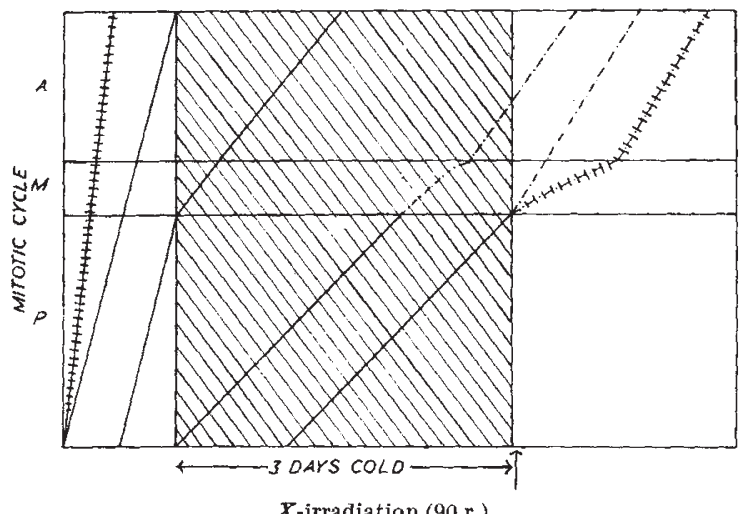

$\boldsymbol{X}$-irradiation (90 r.)

Diagram illustrating the effect of temperature and $X$-rays on by broken line; ++++ , cells which have been submitted to $\mathrm{X}$-irradiation at times marked

The single and combined effects of temperature and X-rays on the speed of mitosis are illustrated in the accompanying graph. It will be seen that, at the dose employed, X-rays speed up mitosis. On the other hand, low temperature slows it down by prolonging prophase ; consequently, in Trillium root-tips it piles up metaphases all showing the nucleic acid - starved heterochromatin condition ${ }^{2}$. In spite of the opposite individual effect of cold and $\mathrm{X}$-rays, when combined their effects are supplementary: they slow down mitosis still further, or indeed may suppress it ${ }^{1}$.

The suppressing effect is complete when irradiation takes place during the cold treatment. It is marked even when irradiation is postponed until the end of the treatment. This is shown by the fact that all the fixations of the irradiated samples show starvation up to $7 \mathrm{hr}$. after treatment. The fixation made at $24 \mathrm{hr}$. shows a new wave of oncoming mitoses, detectable by a reduced starvation of the heterochromatin at metaphase. Without irradiation, this would happen at 3-4 hr. at the same temperature, $20^{\circ} \mathrm{C}$. 